\title{
An update on the pathology and clinical management of gouty arthritis
}

\author{
Emilio B. Gonzalez
}

Received: 2 August 2011 /Revised: 28 September 2011 / Accepted: 12 October 2011 / Published online: 9 November 2011

(C) The Author(s) 2011. This article is published with open access at Springerlink.com

\begin{abstract}
Gouty arthritis is an inflammatory condition associated with debilitating clinical symptoms, functional impairments, and a substantial impact on quality of life. This condition is initially triggered by the deposition of monosodium urate crystals into the joint space. This causes an inflammatory cascade resulting in the secretion of several proinflammatory cytokines and neutrophil recruitment into the joint. While generally effective, currently available agents are associated with a number of adverse events and contraindications that complicate their use. Based on our increased understanding of the inflammatory pathogenesis of gouty arthritis, several new agents are under development that may provide increased efficacy and reduced toxicity.
\end{abstract}

Keywords Chronic diseases · Gouty arthritis ·

Inflammation · Pathophysiology

\section{Introduction}

There are an estimated 5-6 million individuals in the USA with gout [1, 2]. This condition is encountered more commonly in men than women, although among women the prevalence increases after menopause [3]. Prevalence

The author had full control of the contents, and the opinions expressed here are those of the author and not of Novartis Pharmaceuticals Corporation.

E. B. Gonzalez $(\bowtie)$

Division of Rheumatology, Department of Medicine, The

University of Texas Medical Branch (UTMB),

301 University Blvd, Route 0565,

Galveston, TX 77555-0565, USA

e-mail: ebgonzal@utmb.edu also increases dramatically with age, with almost $12 \%$ of males aged $70-79$ years affected compared with $<3 \%$ in men younger than 50 years (Fig. 1) [1, 2]. Given its demographics among the aging population, patients with gout frequently present with multiple comorbidities: up to $58 \%$ of patients with gout have comorbid hypertension, $45 \%$ have a comorbid lipid disorder, 33\% have both hypertension and a lipid disorder, and $20 \%$ have comorbid diabetes mellitus [4]. Gout therefore represents a condition of the aging population where effective management can be frequently complicated by substantial comorbidities.

Urate levels in the body are balanced through diet, biosynthesis, and excretion, with overproduction or insufficient renal clearance leading to chronic hyperuricemia [5]. The pronounced increases in the plasma concentration of urate that occur during chronic hyperuricemia can lead to supersaturation, and at concentrations $>6.8 \mathrm{mg} / \mathrm{dL}$, precipitation of monosodium urate (MSU) crystals can occur [6]. Acute gouty arthritis develops when MSU crystal deposits around a joint are released into the joint space causing inflammation. Until recently, the molecular components of this inflammation were poorly understood. For example, not all individuals with elevated levels of uric acid develop gouty arthritis, there being other factors that potentially facilitate the process. However, recent research has revealed that interleukin (IL)-1 $\beta$ represents a key inflammatory mediator in this pathway, and, as such, a viable therapeutic target. The aim of this review is to summarize the current understanding of the role of IL- $1 \beta$ in the inflammation seen in patients with gouty arthritis and to provide an overview of current treatment options with a focus on recent additions to the therapeutic management of this painful condition. 


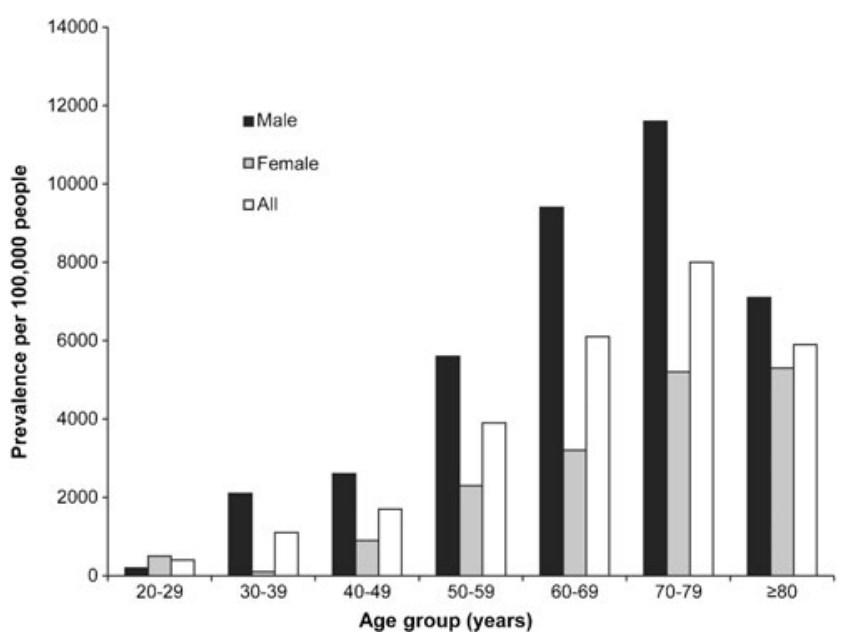

Fig. 1 Prevalence of gout in the USA according to age $[1,2]$

\section{Pathophysiology of gouty arthritis}

Gouty arthritis is caused by the inflammatory reaction that arises in response to the deposition of MSU crystals into the joints of patients with hyperuricemia. This MSU-induced inflammation is driven by components of the innate immune system which normally provide the initial nonspecific immune response to invading pathogens. Research has shown that injured and dying mammalian cells release uric acid, which forms MSU crystals that activate innate immunity in a manner similar to that caused by microbial infection [7]. The initial process of the gouty arthritis inflammatory response occurs when macrophages that are present within the joint space phagocytose MSU crystals (Fig. 2). This internalization of MSU crystals then triggers the formation of a protein scaffold known as an inflammasome within the cytosol of the macrophage. The inflammasome is a high-molecular weight protein complex that provides a platform for the enzymatic processing of inactive pro-IL-1 $\beta$ into biologically active IL- $1 \beta$, which is then secreted from the cell [8]. Interestingly, MSU crystals alone may not be sufficient to trigger the activation/release of IL$1 \beta$ from macrophages, instead requiring co-stimulation with free fatty acids or lipopolysaccharide to release IL$1 \beta$ [9]. Given that the consumption of alcohol or a large meal can lead to increases in free fatty acid concentrations, it stands to reason that the involvement of free fatty acids in triggering release of IL-1 $\beta$ may be an important factor in the development of gouty arthritis flares [9].

IL- $1 \beta$ is the pivotal inflammatory mediator that regulates cell proliferation, differentiation, and apoptosis in gouty arthritis (Fig. 2) [10]. This proinflammatory cytokine can induce the expression of a wide range of inflammatory mediators that are directly responsible for neutrophil influx to the synovium, a hallmark of gouty arthritis [10]. Activation of the IL-1 receptor on endothelial cells by IL-
$1 \beta$ has been shown to be a fundamentally critical step in the development of MSU-induced inflammation using genetic knockout rodent models. IL-1 receptor activation facilitates the transcription of proinflammatory cytokines and chemokines that drive subsequent inflammatory processes $[8,11]$. Furthermore, neutrophil influx results in further phagocytosis of MSU crystals and the perpetuation of both IL-1 $\beta$ release and its associated inflammatory processes. Strategies that reduce circulating IL- $1 \beta$, including antibodies to IL-1 $\beta$ and murine IL-1 trap, have been shown to greatly reduce MSU-induced peritonitis in mice [11].

Over time, the acute inflammation accompanying repeated flares of gouty arthritis can culminate in pathologic joint damage. Prolonged accumulation of MSU crystals gives rise to tophi which consist of MSU crystals in a matrix of lipids, protein, and mucopolysaccharides [12]. Enzymes, such as matrix metalloproteinases, and bone-resorptive osteoclasts are produced locally within these tophi, resulting in progressive bone erosion [12]. In addition, the elevated levels of proinflammatory cytokines that arise during flares of gouty arthritis may also contribute to bone damage. IL-1 is a key molecule in the process of bone and cartilage damage and plays a critical role in osteoclast formation [13].

\section{Management of gouty arthritis}

Treatment of gouty arthritis has three phases: control of the acute attack/flare, control of hyperuricemia, and then prophylaxis.

\section{Acute attack}

During the acute attack, nonsteroidal anti-inflammatory drugs (NSAIDs) and colchicine are considered as first-line treatment for relief of acute pain associated with flares of gouty arthritis (Table 1) [14]. Among the NSAIDs, indomethacin and naproxen have labeled approval for use in acute gouty arthritis while ibuprofen and celecoxib are not approved. Given the potential for gastrointestinal ulceration and bleeding, as well as the exacerbation of common comorbidities in this patient population (e.g., renal dysfunction, hypertension), it is the opinion of this author that the use of nonselective NSAIDs in patients over the age of 65 years be avoided, particularly in the presence of significant underlying renal dysfunction and in elderly patients with a previous history of gastrointestinal ulceration and bleeding.

Colchicine is an established treatment for acute gouty arthritis but only recently has received approval from the US Food and Drug Administration for use in this indication (Colcrys $^{\mathrm{TM}}$ (colchicine, USP) tablets for oral use; Mutual 
Fig. 2 IL-1 $\beta$ signaling leads to recruitment of neutrophils and amplification of an acute inflammatory cascade. IL interleukin, $M S U$ monosodium urate, $T N F-\alpha$ tumor necrosis factor alpha

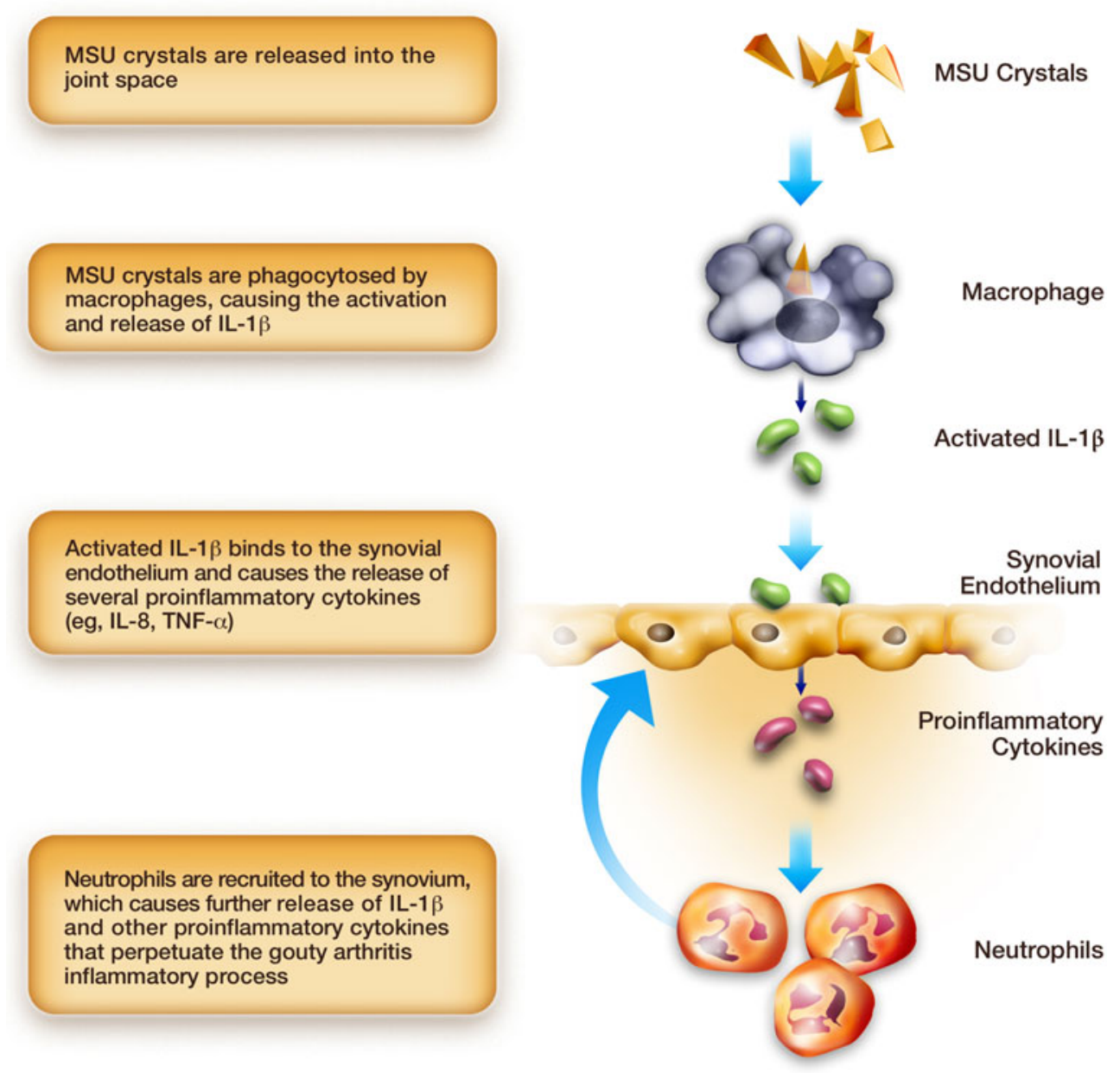

Pharmaceutical Company, Inc., Corona, CA). This approval was based on the results of the placebo-controlled Acute Gout Flare Receiving Colchicine Evaluation study, which demonstrated that colchicine, at low $(1.8 \mathrm{mg})$ or high (4.8 $\mathrm{mg}$ ) doses, administered over $6 \mathrm{~h}$ was significantly more effective than placebo at reducing pain scores. Overall, $32.7 \%$ and $37.8 \%$ of patients receiving high-dose and low-dose colchicine had a $\geq 50 \%$ reduction in pain scores within $24 \mathrm{~h}$ of starting treatment, compared with $15.5 \%$ of those receiving placebo $(p=0.034$ and $p=0.005$ for comparison of high- and low-dose versus placebo, respectively). Diarrhea was the most frequently reported adverse event (AE) among patients receiving colchicine (low dose, 23\%; high dose, 76.9\%) [15].

Systemic corticosteroids are a treatment option for patients who have contraindications to NSAIDs and colchicine, or who do not tolerate these first-line agents; however, this approach is not underscored by robust clinical trial data (Table 1) [14]. Intraarticular injection of a longacting steroid is another potential therapeutic approach that may be effective at alleviating pain associated with an acute monoarticular attack [14, 16].
Analysis of contraindications and prescribing practices suggests that a large number of patients with gout have contraindications to the currently available therapies [17]. In a retrospective database analysis of 807 patients with an International Classification of Diseases, Ninth Revision, Clinical modification (ICD-9-CM) code diagnosis for gout, the prevalence of comorbidities and contraindications to gout medications was high. In total, $89 \%$ of patients with gout had hypertension, $63 \%$ had hyperlipidemia, $47 \%$ had chronic kidney disease, $37 \%$ had coronary artery disease, and $28.9 \%$ had diabetes. In addition, most patients had multiple comorbidities with two, three, or four comorbidities present in $17 \%, 22 \%$, and $25 \%$ of patients, respectively. The presence of these comorbidities also translated into high rates of contraindications to gout therapy. More than $90 \%$ of patients had $\geq 1$ contraindication to NSAID use, $95 \%$ had $\geq 1$ contraindication to glucocorticoid use, and at least $50 \%$ had at least one contraindication to colchicine use. In this study, each patient had a mean of 3.5 contraindications to gout drugs [17].

This ineligibility for current treatment that exists among a large number of patients with gout has resulted in the 


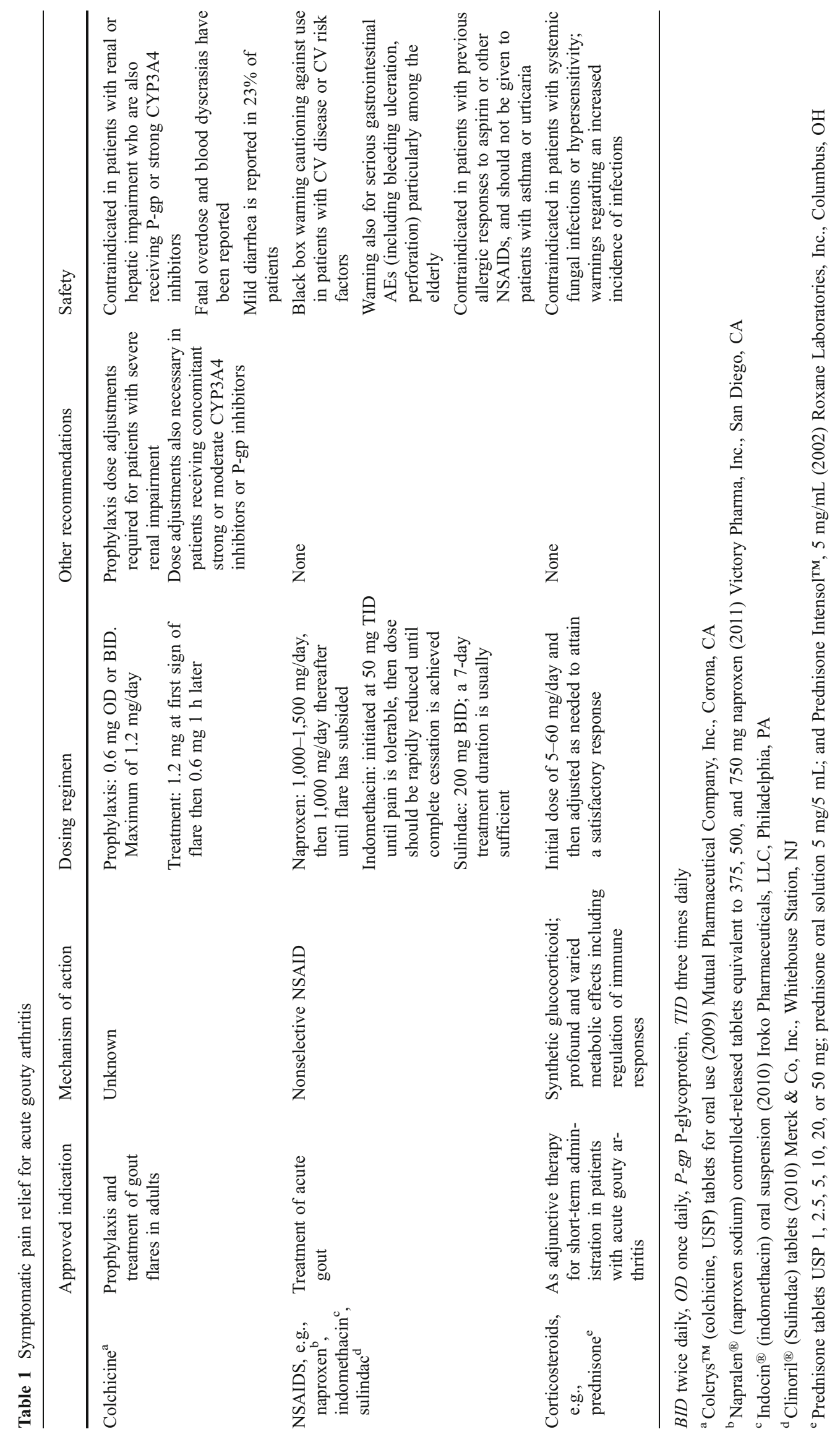


need for alternative treatment options. One such therapeutic alternative has arisen from the increasing understanding of the role of IL-1 $\beta$ in the underlying inflammatory response seen in gouty arthritis. Treatment strategies that aim to interrupt the IL-1 $\beta$ molecular pathway will theoretically reduce the inflammation and pain experienced by patients during flares of gouty arthritis, and clinically, this treatment approach has shown considerable early promise.

\section{New therapeutic agents studied for acute management: IL-1 $\beta$ signaling blockade}

Anakinra is a recombinant, nonglycosylated form of the human IL-1 receptor antagonist approved for use in patients with moderate to severely active rheumatoid arthritis who have failed first-line therapies. Studies in patients with gout are restricted to small case series in ten or fewer patients $[18,19]$. In one case series, patients with a history of recurrent gouty arthritis or tophaceous gout received openlabel anakinra at a dose of $100 \mathrm{mg} /$ day administered as a subcutaneous injection for 3 days [19]. All patients responded rapidly to treatment, with a mean decrease in pain rating of $79 \%$ by day 3 after the initial injection. Another case series of ten patients also reported favorable short-term responses to anakinra; however, recurrent flares after discontinuation of treatment were common, occurring in nine of ten treated patients [18].

A small proof-of-concept study has investigated the efficacy and safety of rilonacept, a soluble receptor-Fc fusion protein trap for and inhibitor of IL- $1 \alpha$ and IL- $1 \beta$, in the treatment of chronic gouty arthritis [20]. In this 14-week study, ten patients with chronic active gouty arthritis underwent a 2-week lead-in period (during which patients received single-blind placebo) and then received rilonacept for 6 weeks followed by a 6-week follow-up period. Rilonacept was administered as a single loading dose of $320 \mathrm{mg}$ during week 2 followed by $160 \mathrm{mg}$ once weekly during weeks 3-7. Compared with the placebo run-in phase, treatment with rilonacept was associated with a significant improvement in patient pain scores, global assessment of "feeling well" and symptom/severity adjusted scores. There was also a significant reduction in levels of high-sensitivity C-reactive protein (CRP) compared with the lead-in phase. One patient discontinued during the second week of active treatment because of severe injection site erythema and induration related to study medication, and three patients developed anti-rilonacept antibodies [20].

Canakinumab (ACZ885) is a fully human monoclonal antibody that neutralizes the activity of human IL-1 $\beta$, leading to inhibition of IL- $1 \beta$ signaling and suppression of inflammation [21]. It has shown activity in small studies of patients with rheumatoid arthritis and cryopyrin-associated periodic syndrome and is approved in the USA and Switzerland for treatment of Muckle-Wells syndrome and familial cold autoinflammatory syndrome [21]. In a phase 2 dose-ranging study in patients with difficult-to-treat gouty arthritis, canakinumab $(10,25,50,90$, and $150 \mathrm{mg}$ as single intramuscular doses) was associated with a dose-related decline in pain rating at $72 \mathrm{~h}$ after administration [22]. At the highest dose, canakinumab resulted in a significantly greater mean reduction in pain compared with intramuscular injection of triamcinolone acetonide $(40 \mathrm{mg})$ at $24 \mathrm{~h}, 48 \mathrm{~h}$, $72 \mathrm{~h}, 4,5$, and 7 days after dosing. All doses evaluated resulted in a numerically greater reduction in pain at $72 \mathrm{~h}$ (as assessed using a visual analog scale) compared with triamcinolone acetonide; however, evaluation of pain levels at $48 \mathrm{~h}$ postinjection indicates that a canakinumab dose of $23 \mathrm{mg}$ (95\% confidence interval [CI], 3-96 mg) has equivalent efficacy to triamcinolone acetonide $(40 \mathrm{mg})$. Furthermore, the incidence of flare at 8 weeks posttreatment was $3.7 \%$ in patients receiving canakinumab $(150 \mathrm{mg})$ and $45 \%$ in those who received triamcinolone acetonide. Canakinumab treatment (at doses 20-150 mg) was also associated with normalization of CRP and serum amyloid A protein (SAA) levels by day 7 after treatment; however, these inflammatory markers were largely unaffected by triamcinolone acetonide. There were four serious AEs in patients receiving canakinumab (appendicitis, $n=2$; bronchitis, $n=1$; and carotid artery stenosis, $n=1$ ), all considered to be unrelated to study medication. The tolerability profile was otherwise similar in patients receiving canakinumab and triamcinolone acetonide [22]. Subsequent analyses of the data from this study have reported that at a dose of $150 \mathrm{mg}$, canakinumab shows superiority over triamcinolone acetonide $(40 \mathrm{mg})$ in terms of pain relief, reduction in signs of inflammation (as assessed using a Likert scale and also through inflammatory markers), and health-related quality of life measures [23]. Additional phase 3 studies of canakinumab in patients with gouty arthritis are ongoing [21].

Agents that interfere with IL- $1 \beta$ signaling therefore appear to represent an important therapeutic class in the future treatment of gouty arthritis; however, clinical experience with these agents in patients with rheumatoid arthritis suggests that their use may be associated with an increased risk of infection [24]. At this time, the extent to which this association is related to comorbidities that are unique to patients with rheumatoid arthritis is unknown. Data from additional randomized controlled trials in patients with gouty arthritis will help provide a better understanding regarding the benefit-risk profile of these agents.

\section{Chronic management}

In patients who experience recurring flares of gouty arthritis, long-term chronic management strategies should be implemented to mitigate the incidence of acute attacks. 


\section{Lifestyle modification}

Weight reduction is recommended for overweight or obese patients [16], supplemented by an increased intake of selected food types. Patients should be encouraged to include skimmed milk, low-fat yogurt, soy beans, vegetable protein sources, and cherries in their diets, and high-purine foods such as liver, kidney, shellfish, and red meat should be discouraged $[16,25,26]$. Alcohol consumption $<21$ units/week for men and $<14$ units per week for women is also strongly advised - beer, stout, and port should be avoided, and patients should be encouraged to maintain 3 days each week in which alcohol is completely avoided [16]. Finally, management strategies should also take into account concomitant medications that could increase serum uric acid levels. Thiazide or loop diuretics, low-dose aspirin, cyclosporine, niacin, pyrazinamide, and ethambutol may each cause increased serum uric acid levels [6].

\section{Pharmacologic management}

Patients who experience recurrent acute attacks, arthropathy, tophi, or radiographic changes are candidates for uratelowering therapy (Table 2) [14]. The therapeutic goal is to promote crystal dissolution and prevent crystal formation by maintaining serum urate concentrations below the saturation point for MSU $[14,16]$.

Allopurinol and probenecid have for many years represented the cornerstone of treatment for chronic gouty arthritis. Allopurinol, a xanthine oxidase inhibitor that acts by blocking the production of uric acid through a reduction in purine catabolism, is considered to be an appropriate long-term urate-lowering therapy (Table 2) [14]. Typical AEs associated with allopurinol include diarrhea, nausea, and increases in alkaline phosphatase, ALT, and AST levels (Allopurinol (tablet); Watson Laboratories, Inc., Corona, CA). Probenecid is a uricosuric agent that increases excretion of uric acid by blocking tubular reabsorption (Table 2) (Probenecid; Watson Pharmaceuticals Inc., Corona, CA). It is used largely as an alternative to allopurinol, although it is considered less efficacious [14].

Febuxostat is a more recent addition to treatment options for chronic gouty arthritis. It is a nonpurine, xanthine oxidase inhibitor approved for the chronic management of hyperuricemia in patients with gouty arthritis (Table 2) (Uloric ${ }^{\circledR}$ (Febuxostat) tablet for oral use; Takeda Pharmaceuticals America, Inc., Deerfield, IL). Like allopurinol, febuxostat inhibits the synthesis of uric acid by xanthine oxidase. However, animal studies have suggested it provides a more potent and longer-lasting hypouricemic effect compared with allopurinol, an effect attributed to its potent inhibition of both oxidized and reduced forms of xanthine oxidase [27]. The approval of febuxostat was based on the data from three phase 3 clinical trials, Allopurinol- and Placebo-controlled Efficacy study of febuxostat (APEX) [28], Febuxostat versus Allopurinol Controlled Trial (FACT) [29], and CONFIRMS [30].

The phase 3 clinical studies showed febuxostat $(80$ $240 \mathrm{mg} /$ day) to be significantly more effective than allopurinol (200-300 mg/day). In all studies, the proportion of patients with a urate concentration $<6 \mathrm{mg} / \mathrm{dL}$ at the end of treatment (the primary end point) was significantly higher among patients receiving febuxostat compared with allopurinol [28-30]. However, it is also noteworthy that these studies did not allow for allopurinol to be dose titrated above $300 \mathrm{mg} /$ day, despite higher doses being recommended for patients with moderately severe tophaceous gout (Allopurinol (tablet); Watson Laboratories, Inc., Corona, CA). In APEX and FACT, prophylaxis against gout flares with naproxen $(250 \mathrm{mg}$ twice daily) or colchicine $(0.6 \mathrm{mg} /$ day $)$ was administered for the first 8 weeks of treatment, and in both studies the incidence of gout flares was highest during the 4 weeks immediately following withdrawal of prophylaxis [31]. However, in CONFIRMS, prophylaxis for gout flares was administered for the full 6-month treatment period, and unlike the previous two studies, there was no peak in the incidence of flares at weeks 9-12, but instead a steady decline in the incidence of flares throughout the 6-month treatment period [32].

Overall, AEs were similar across all treatment groups in these studies [28-30]. In APEX, febuxostat at $240 \mathrm{mg} /$ day was associated with high levels of diarrhea and dizziness, and the incidence of hypertension was also higher in the febuxostat $80-\mathrm{mg} /$ day arm [28]. Abnormal findings on liver function tests and rash-related AEs were generally similar across treatment arms, and AEs leading to treatment withdrawal were similar in patients receiving febuxostat and allopurinol [28]. In FACT, the incidence of treatmentrelated AEs was also similar between treatment arms, with liver function abnormalities, diarrhea, and headache occurring at a similar incidence in each treatment arm. Abnormal liver function tests and rash were the most frequent AEs leading to treatment discontinuation in patients receiving febuxostat [29]. In CONFIRMS, rash, liver function abnormalities, and diarrhea occurred at broadly similar rates in patients receiving febuxostat or allopurinol [30]. Premature treatment withdrawal because of an AE was also similar across treatment arms (6.5-8.5\%) [30]. Overall, pooled study data of the most frequently reported AEs for febuxostat and allopurinol showed similar rates of liver function abnormalities (4.6-6.6\% vs $4.2 \%$, respectively), nausea $(1.1-1.3 \%$ vs $0.8 \%$, respectively), arthralgia $(0.7-$ $1.1 \%$ vs $0.7 \%$, respectively), and rash $(0.5-1.6 \%$ vs $1.6 \%$, respectively) (Allopurinol (tablet); Watson Laboratories, Inc., Corona, CA). 
Table 2 Therapeutic options for chronic hyperuricemia and treatment refractory gouty arthritis

\begin{tabular}{|c|c|c|c|c|c|}
\hline & $\begin{array}{l}\text { Approved } \\
\text { indication }\end{array}$ & $\begin{array}{l}\text { Mechanism } \\
\text { of action }\end{array}$ & Dosing regimen & $\begin{array}{l}\text { Other } \\
\text { recommendations }\end{array}$ & Safety \\
\hline \multicolumn{6}{|l|}{$\begin{array}{l}\text { Chronic } \\
\text { hyperuricemia }\end{array}$} \\
\hline \multirow[t]{3}{*}{ Allopurinol $^{\mathrm{a}}$} & $\begin{array}{l}\text { Management of } \\
\text { patients with } \\
\text { signs and } \\
\text { symptoms of } \\
\text { primary or } \\
\text { secondary gout }\end{array}$ & $\begin{array}{l}\text { Xanthine } \\
\text { oxidase } \\
\text { inhibitor }\end{array}$ & $\begin{array}{l}\text { Starting dose of } 100 \mathrm{mg} / \text { day } \\
\text { increasing at } 100-\mathrm{mg} / \text { day } \\
\text { increments each week until } \\
\text { sUA } \leq 6 \mathrm{mg} / \mathrm{dL}\end{array}$ & $\begin{array}{l}\text { Prophylaxis with } \\
\text { colchicine or NSAID } \\
\text { to suppress gouty } \\
\text { attacks as needed }\end{array}$ & $\begin{array}{l}\text { Contraindicated in patients } \\
\text { with history of severe } \\
\text { reaction to allopurinol }\end{array}$ \\
\hline & & & $\begin{array}{l}\text { Maximum recommended } \\
\text { dose }=800 \mathrm{mg} / \text { day }\end{array}$ & $\begin{array}{l}\text { Maintain fluid intake to } \\
\text { yield daily urine output } \\
\text { of } \geq 2 \text { L }\end{array}$ & $\begin{array}{l}\text { Skin rash can be severe and } \\
\text { sometimes fatal }\end{array}$ \\
\hline & & & & $\begin{array}{l}\text { Discontinue at the first } \\
\text { sign of rash }\end{array}$ & $\begin{array}{l}\text { Other AEs include diarrhea, } \\
\text { nausea, and alkaline } \\
\text { phosphatase increase }\end{array}$ \\
\hline \multirow[t]{3}{*}{ Febuxostat $^{\mathrm{c}}$} & $\begin{array}{l}\text { Chronic } \\
\text { management of } \\
\text { hyperuricemia } \\
\text { in patients with } \\
\text { gout }\end{array}$ & $\begin{array}{l}\text { Xanthine } \\
\text { oxidase } \\
\text { inhibitor }\end{array}$ & $\begin{array}{l}40 \mathrm{mg} \text { OD, increasing to } 80 \mathrm{mg} \\
\text { OD after } 1 \text { week in patients } \\
\text { with } \mathrm{sUA} \geq 6 \mathrm{mg} / \mathrm{dL}\end{array}$ & $\begin{array}{l}\text { Prophylaxis with } \\
\text { NSAID or colchicine } \\
\text { for up to } 6 \text { months } \\
\text { recommended to } \\
\text { minimize gout flares }\end{array}$ & $\begin{array}{l}\text { Contraindicated in patients } \\
\text { receiving azathioprine or } \\
\text { mercaptopurine }\end{array}$ \\
\hline & & & & & $\begin{array}{l}\text { Cardiovascular } \\
\text { thromboembolic events and } \\
\text { liver enzyme elevations may } \\
\text { be more common }\end{array}$ \\
\hline & & & & & $\begin{array}{l}\text { Other AEs include nausea, } \\
\text { arthralgia, and rash }\end{array}$ \\
\hline \multirow[t]{2}{*}{ Probenecid $^{\mathrm{d}}$} & $\begin{array}{l}\text { Treatment of } \\
\text { hyperuricemia } \\
\text { associated with } \\
\text { gout and gouty } \\
\text { arthritis }\end{array}$ & $\begin{array}{l}\text { Uricosuric } \\
\text { agent which } \\
\text { blocks } \\
\text { tubular } \\
\text { reabsorption } \\
\text { of uric acid }\end{array}$ & $\begin{array}{l}250 \mathrm{mg} \text { BID for } 1 \text { week, then } \\
500 \mathrm{mg} \text { BID thereafter }\end{array}$ & $\begin{array}{l}\text { Alkalization of the urine } \\
\text { with sodium } \\
\text { bicarbonate }(3-7.5 \mathrm{~g} / \\
\text { day) or potassium } \\
\text { citrate }(7.5 \mathrm{~g} / \text { day }) \\
\text { recommended }\end{array}$ & $\begin{array}{l}\text { Contraindicated in patients with } \\
\text { hypersensitivity to } \\
\text { probenecid, children aged } \\
<2 \text { years, and is not } \\
\text { recommended in patients with } \\
\text { known blood dyscrasias or } \\
\text { uric acid kidney stones }\end{array}$ \\
\hline & & & & $\begin{array}{l}\text { Colchicine or alternative } \\
\text { symptomatic therapy } \\
\text { advised for patients } \\
\text { with exacerbation of } \\
\text { gout following therapy }\end{array}$ & \\
\hline \multicolumn{6}{|l|}{$\begin{array}{l}\text { Treatment } \\
\text { refractory } \\
\text { disease }\end{array}$} \\
\hline \multirow[t]{2}{*}{ Pegloticase $^{\mathrm{f}}$} & $\begin{array}{l}\text { Treatment of } \\
\text { chronic gout in } \\
\text { adult patients } \\
\text { refractory to } \\
\text { conventional } \\
\text { therapy }\end{array}$ & $\begin{array}{l}\text { Pegylated } \\
\text { uricase } \\
\text { enzyme }\end{array}$ & $\begin{array}{l}8 \text { mg as an intravenous infusion } \\
\text { every } 2 \text { weeks premedicated } \\
\text { with antihistamines and } \\
\text { corticosteroids; optimal } \\
\text { treatment duration not } \\
\text { established }\end{array}$ & $\begin{array}{l}\text { Prophylaxis with } \\
\text { NSAID or colchicine } \\
\text { recommended to } \\
\text { minimize gout flares }\end{array}$ & $\begin{array}{l}\text { Black box warning for } \\
\text { anaphylaxis and infusion } \\
\text { related reactions }\end{array}$ \\
\hline & & & & $\begin{array}{l}\text { Discontinue therapy in } \\
\text { patients with uric acid } \\
\text { levels }>6 \mathrm{mg} / \mathrm{dL}^{\mathrm{g}}\end{array}$ & $\begin{array}{l}\text { Contraindicated in patients } \\
\text { with glucose-6-phosphate } \\
\text { dehydrogenase deficiency }\end{array}$ \\
\hline \multicolumn{6}{|c|}{$B I D$ twice daily, $O D$ once daily, $s U A$ serum uric acid } \\
\hline \multicolumn{6}{|c|}{ a Allopurinol (tablet) (2006) Watson Laboratories, Inc., Corona, CA } \\
\hline \multicolumn{6}{|c|}{${ }^{\mathrm{b}}$ Acute attacks, tophi, joint destruction, uric acid lithiasis, and/or nephropathy } \\
\hline \multicolumn{6}{|c|}{${ }^{\mathrm{c}}$ Uloric ${ }^{\circledR}$ (Febuxostat) tablet for oral use (2009) Takeda Pharmaceuticals America, Inc., Deerfield, IL } \\
\hline \multicolumn{6}{|c|}{${ }^{\mathrm{d}}$ Probenecid (2011) Watson Pharmaceuticals Inc., Corona, CA } \\
\hline \multicolumn{6}{|c|}{${ }^{\mathrm{e}}$ Daily dose can be increased up to a maximum of $2,000 \mathrm{mg} /$ day in patients with uncontrolled hyperuricemia or with renal impairment } \\
\hline
\end{tabular}




\section{Treatment of refractory or tophaceous gouty arthritis}

Most mammals possess the enzyme urate oxidase that catalyzes the conversion of uric acid to 5-hydroxy isourate and hydrogen peroxide, ultimately leading to the formation of allantoin, which is a more soluble and easily excreted purine metabolite [33, 34]. However, as a result of mutations to the urate oxidase gene during evolution, this pathway for urate elimination is not functional in humans. Pegloticase is a genetically engineered pegylated mammalian urate oxidase enzyme indicated for the treatment of chronic gout in adult patients refractory to conventional therapy, such as those who have failed to achieve normal serum urate levels or whose symptoms are inadequately controlled with xanthine oxidase inhibitors at the maximum tolerated dose (Table 2) (KRYSTEXXA ${ }^{\mathrm{TM}}$ (pegloticase) injection, for intravenous infusion; Savient Pharmaceuticals, Inc., East Brunswick, NJ).

In a randomized phase 2 study of 41 patients with gouty arthritis who had been unsuccessfully treated with, or had contraindication to, urate-lowering therapy, pegloticase at doses of 4 or $8 \mathrm{mg}$ every 2 weeks, or 8 or $12 \mathrm{mg}$ every 4 weeks, was associated with a rapid decrease in plasma urate levels to $\leq 6 \mathrm{mg} / \mathrm{dL}$ [34]. This decrease was seen within $6 \mathrm{~h}$ of commencing treatment, and was sustained for the 10-week treatment period in all dose groups, except the 4-mg-every-2weeks group. Two patients experienced rapid regression of tophi within 12 weeks of starting treatment [35]. The most commonly reported AEs were nephrolithiasis (15\%) and arthralgia (12\%), followed by anemia, dyspnea, headache, muscle spasms, nausea, and pyrexia, each reported in $10 \%$ of patients. Overall, $76 \%$ of patients showed anti-pegloticase immunoreactivity during the study, which was associated with a shortened pegloticase half-life and an increase in urate area under the curve. Among patients who were antibody negative, treatment response was $100 \%$ [34].

Subsequent phase 3 studies have also confirmed the urate-lowering ability of pegloticase in patients with severe gouty arthritis who are refractory or intolerant to allopurinol and with serum urate $\geq 8 \mathrm{mg} / \mathrm{dL}$ [36]. In two 24-week, randomized, double-blind, placebo-controlled studies, the proportion of patients with plasma urate levels $<6 \mathrm{mg} / \mathrm{dL}$ for $\geq 80 \%$ of the time during months 3 and 6 (corresponding to the 4-week periods immediately following week 9 and week 21 infusions) was significantly higher in patients receiving pegloticase ( $8 \mathrm{mg}$ biweekly or every 4 weeks) compared with those receiving placebo ( $42 \%$ and $35 \%$ vs $0 \%, p<0.001$ for both comparisons). Complete response in one or more tophi (defined as $100 \%$ reduction in tophus area) was seen in $40 \%$ of patients receiving biweekly pegloticase, $21 \%$ of those receiving monthly pegloticase, and $7 \%$ of those receiving placebo (biweekly vs placebo, $p=0.002$; monthly vs placebo $p=$
0.2). Pegloticase antibodies were present in 134 of 150 treated patients and were significantly associated with an impaired response to therapy and a higher risk of infusionrelated reactions. Gout flares (despite prophylaxis with colchicine or NSAIDs throughout the study) and infusionrelated reactions (despite pretreatment with fexofenadine, acetaminophen, and hydrocortisone) were the most frequently reported AEs [36].

\section{Summary}

Gouty arthritis is the most common type of inflammatory arthritis in males over the age of 40 years. Unfortunately, it is also one of the most misunderstood diseases. Oversaturation of serum urate and formation of MSU crystals activates the inflammasome, resulting in the maturation of IL- $1 \beta$, a proinflammatory cytokine. This begins a cascade of events that culminates in neutrophil influx into the synovium and the highly inflammatory nature of acute gouty arthritis. Management of this condition requires treatment of the acute attack, addressing the underlying metabolic abnormality of the hyperuricemia, and providing prophylaxis to the patient to prevent recurrence until normouricemia is achieved. Unfortunately, a large proportion of especially elderly patients are either unresponsive to or intolerant of the use of currently available medications such as xanthine oxidase inhibitors and NSAIDs because of the presence of significant comorbidities such as renal failure, cardiovascular disease, or being at risk for gastrointestinal bleeding. In these patients, the advent of IL-1 blockade represents a promising new treatment modality. Results from the completed phase 3 studies of these agents, once available, will help us to better understand their benefitrisk ratio.

Acknowledgments Editorial assistance for this manuscript was funded by Novartis Pharmaceuticals Corporation and provided by Santo D'Angelo, Ph.D., MS, of ApotheCom.

Disclosures Dr. Gonzalez is on the speakers' bureau of Takeda and Savient Pharmaceuticals and is participating in sponsored clinical trials for Pfizer and A/B Science.

Open Access This article is distributed under the terms of the Creative Commons Attribution Noncommercial License which permits any noncommercial use, distribution, and reproduction in any medium, provided the original author(s) and source are credited.

\section{References}

1. Kramer HM, Curhan G (2002) The association between gout and nephrolithiasis: the National Health and Nutrition Examination Survey III, 1988-1994. Am J Kidney Dis 40(1):37-42 
2. Lawrence RC, Felson DT, Helmick CG et al (2008) Estimates of the prevalence of arthritis and other rheumatic conditions in the United States. Part II. Arthritis Rheum 58 (1):26-35

3. Wallace KL, Riedel AA, Joseph-Ridge N, Wortmann R (2004) Increasing prevalence of gout and hyperuricemia over 10 years among older adults in a managed care population. J Rheumatol 31 (8): $1582-1587$

4. Riedel AA, Nelson M, Wallace K et al (2004) Prevalence of comorbid conditions and prescription medication use among patients with gout and hyperuricemia in a managed care setting. J Clin Rheumatol 10(6):308-314

5. Choi HK, Mount DB, Reginato AM (2005) Pathogenesis of gout. Ann Intern Med 143(7):499-516

6. Becker MA, Ruoff GE (2010) What do I need to know about gout? J Fam Pract 59(6 Suppl):S1-S8

7. Shi Y, Evans JE, Rock KL (2003) Molecular identification of a danger signal that alerts the immune system to dying cells. Nature 425(6957):516-521

8. Martinon F, Petrilli V, Mayor A, Tardivel A, Tschopp J (2006) Gout-associated uric acid crystals activate the NALP3 inflammasome. Nature 440(7081):237-241

9. Joosten LA, Netea MG, Mylona E et al (2010) Engagement of fatty acids with Toll-like receptor 2 drives interleukin-1beta production via the ASC/caspase 1 pathway in monosodium urate monohydrate crystal-induced gouty arthritis. Arthritis Rheum 62 (11):3237-3248

10. Pope RM, Tschopp J (2007) The role of interleukin-1 and the inflammasome in gout: implications for therapy. Arthritis Rheum 56(10):3183-3188

11. Torres R, Macdonald L, Croll SD et al (2009) Hyperalgesia, synovitis and multiple biomarkers of inflammation are suppressed by interleukin 1 inhibition in a novel animal model of gouty arthritis. Ann Rheum Dis 68(10):1602-1608

12. Schlesinger N, Thiele RG (2010) The pathogenesis of bone erosions in gouty arthritis. Ann Rheum Dis 69(11):1907-1912

13. Zwerina J, Redlich K, Polzer K et al (2007) TNF-induced structural joint damage is mediated by IL-1. Proc Natl Acad Sci USA 104(28):11742-11747

14. Zhang W, Doherty M, Bardin T et al (2006) EULAR evidence based recommendations for gout. Part II: Management. Report of a task force of the EULAR Standing Committee for International Clinical Studies Including Therapeutics (ESCISIT). Ann Rheum Dis 65(10): 1312-1324

15. Terkeltaub RA, Furst DE, Bennett K et al (2010) High versus low dosing of oral colchicine for early acute gout flare: Twenty-fourhour outcome of the first multicenter, randomized, double-blind, placebo-controlled, parallel-group, dose-comparison colchicine study. Arthritis Rheum 62(4):1060-1068

16. Jordan KM, Cameron JS, Snaith M et al (2007) British Society for Rheumatology and British Health Professionals in Rheumatology guideline for the management of gout. Rheumatology (Oxford) 46 (8):1372-1374

17. Keenan RT, O'Brien WR, Lee KH et al (2011) Prevalence of contraindications and prescription of pharmacologic therapies for gout. Am J Med 124(2):155-163

18. Chen K, Fields T, Mancuso CA, Bass AR, Vasanth L (2010) Anakinra's efficacy is variable in refractory gout: report of ten cases. Semin Arthritis Rheum 40(3):210-214

19. So A, De ST, Revaz S, Tschopp J (2007) A pilot study of IL-1 inhibition by anakinra in acute gout. Arthritis Res Ther 9(2):R28

20. Terkeltaub R, Sundy JS, Schumacher HR et al (2009) The interleukin 1 inhibitor rilonacept in treatment of chronic gouty arthritis: results of a placebo-controlled, monosequence crossover, non-randomised, single-blind pilot study. Ann Rheum Dis 68 (10): $1613-1617$

21. Dhimolea E (2010) Canakinumab. MAbs 2(1):3-13

22. So A, De MM, Pikhlak A et al (2010) Canakinumab for the treatment of acute flares in difficult-to-treat gouty arthritis: Results of a multicenter, phase II, dose-ranging study. Arthritis Rheum 62 (10):3064-3076

23. Schlesinger N, De MM, Pikhlak A et al (2011) Canakinumab relieves symptoms of acute flares and improves health-related quality of life in patients with difficult-to-treat gouty arthritis by suppressing inflammation: results of a randomized, dose-ranging study. Arthritis Res Ther 13(2):R53

24. Salliot C, Dougados M, Gossec L (2009) Risk of serious infections during rituximab, abatacept and anakinra treatments for rheumatoid arthritis: meta-analyses of randomised placebocontrolled trials. Ann Rheum Dis 68(1):25-32

25. Choi HK, Atkinson K, Karlson EW, Willett W, Curhan G (2004) Purine-rich foods, dairy and protein intake, and the risk of gout in men. N Engl J Med 350(11):1093-1103

26. Choi HK, Atkinson K, Karlson EW, Willett W, Curhan G (2004) Alcohol intake and risk of incident gout in men: a prospective study. Lancet 363(9417):1277-1281

27. Becker MA, Schumacher HR Jr, Wortmann RL et al (2005) Febuxostat, a novel nonpurine selective inhibitor of xanthine oxidase: a twenty-eight-day, multicenter, phase II, randomized, double-blind, placebo-controlled, dose-response clinical trial examining safety and efficacy in patients with gout. Arthritis Rheum 52(3):916-923

28. Schumacher HR Jr, Becker MA, Wortmann RL et al (2008) Effects of febuxostat versus allopurinol and placebo in reducing serum urate in subjects with hyperuricemia and gout: a 28 -week, phase III, randomized, double-blind, parallel-group trial. Arthritis Rheum 59(11):1540-1548

29. Becker MA, Schumacher HR Jr, Wortmann RL et al (2005) Febuxostat compared with allopurinol in patients with hyperuricemia and gout. N Engl J Med 353(23):2450-2461

30. Becker MA, Schumacher HR, Espinoza LR et al (2010) The urate-lowering efficacy and safety of febuxostat in the treatment of the hyperuricemia of gout: the CONFIRMS trial. Arthritis Res Ther 12(2):R63

31. Becker MA, Macdonald PA, Hunt BJ, Lademacher C, JosephRidge N (2008) Determinants of the clinical outcomes of gout during the first year of urate-lowering therapy. Nucleosides Nucleotides Nucleic Acids 27(6):585-591

32. Wortmann RL, Macdonald PA, Hunt B, Jackson RL (2010) Effect of prophylaxis on gout flares after the initiation of urate-lowering therapy: analysis of data from three phase III trials. Clin Ther 32 (14):2386-2397

33. Hershfield MS, Roberts LJ, Ganson NJ et al (2010) Treating gout with pegloticase, a PEGylated urate oxidase, provides insight into the importance of uric acid as an antioxidant in vivo. Proc Natl Acad Sci USA 107(32):14351-14356

34. Sundy JS, Becker MA, Baraf HSB et al (2008) Reduction of plasma urate levels following treatment with multiple doses of pegloticase (polyethylene glycol-conjugated uricase) in patients with treatment-failure gout: results of a phase II randomized study. Arthritis Rheum 58(9):2882-2891

35. Baraf HBB, Matsumoto AK, Maroli AM, Waltrip RW (2008) Resolution of gouty tophi after twelve weeks of pegloticase treatment. Arthritis Rheum 58(11):3632-3634

36. Sundy JS, Baraf HS, Yood RA et al (2011) Efficacy and tolerability of pegloticase for the treatment of chronic gout in patients refractory to conventional treatment: two randomized controlled trials. JAMA 306(7):711-720 